\title{
High Qualification Female Tennis Players Physical Fitness
}

\author{
Skorodumova A.P. \\ Federal Science Center for Physical Culture and Sport \\ Moscow, Russia \\ apskorodumova@mail.ru
}

\author{
Baranov I.S. \\ Federal Science Center for Physical Culture and Sport \\ Moscow, Russia \\ ibaranov1805@mail.ru
}

\begin{abstract}
High qualification female tennis players physical fitness problem is discussed in this article. The results of the conducted researches are presented - indicators of total body size, physical and functional fitness at different stages of training and their comparative analysis. The authors conclude that the reason for the lack of reliable statistically significant differences in the indicators of physical and functional fitness of female tennis players training at the stage of sports improvement (SSI) and highest sports skill (HSS) should become the basis for correction entering into the training process of senior tennis players at the stage of HSS for the purpose of its optimization and efficiency increase.
\end{abstract}

Keywords—physical and functional fitness; tennis players of high qualification; stage of sports improvement (SSI) and the highest sports skill (HSS); comparative analysis.

\section{INTRODUCTION}

For optimal conduct of training process knowledge of athletes physical fitness training at different stages of longterm training is necessary. As the results of the reseaches show, the indicators of physical and functional fitness depend on the age of those involved and the stages of preparation $[1,2,3]$.

Earlier in tennis there were revealed differences of athletes aerobic abilities depending on level of skill, and also estimated tables of physical and functional fitness indicators for male tennis players of different ages were developed $[4,5,6,7]$.

However, comparative analysis of female tennis players physical fitness and separate indicators differences identification determining athletes specificity of fitness at certain stage of training were not carried out.

The purpose of research - to determine and compare indicators of athletes physical and functional fitness training at the stages of sports improvement and higher sports skill.

\section{RESEARCH METHODOLOGY}

The study was attended by female tennis players of high qualification 14-16 years old, training at the stage of sports improvement and higher sports skill at the age of 17 years and older. Standardized methods of research were used: anthropometry, ergometry, gasometry, pulsometry and tests of pedagogical control.

To assess physical fitness of female tennis players tests were used, in due time specially selected and now widely used in work with tennis players [5].

During testing speed abilities, the main forms of speed manifestation were determined - speed of simple and complex reaction, single movement speed, speed acceleration, frequency of movements.

In assessing the high speed-power abilities, the capabilities of lower extremity muscles manifested in different directions (up and forward) and upper shoulder belt muscles were evaluated.

In assessing coordination abilities, differentiation of muscle efforts, spatial accuracy of movements, ability to rebuild movements were assessed.

To assess flexibility, the overall flexibility and mobility of the shoulder joints were determined.

Endurance types were evaluated in tests determining alactate and lactate anaerobic endurance.

Determination of aerobic abilities indicators was carried out during athletes running on tredban with step-increasing load until tennis player refused to continue work. Running time at each stage - 2 minutes. Capacity, power and efficiency of aerobic productivity were determined.

The determination of alactate anaerobic productivity was carried out during the maximum 6-second work on a bike ergometer with the fastest rotation of pedals.

\section{RESULTS}

Table I shows the total body sizes of female tennis players training at different stages of long-term training. 
TABLE I. TOTAL BODY SIZES OF HIGH LEVEL MASTERSHIP FEMALE TENNIS PLAYERS TRAINING AT STAGES OF SPORTS IMPROVEMENT AND HIGHER SPORTS SKILL

\begin{tabular}{|c|c|c|c|c|c|c|c|c|}
\hline \multicolumn{2}{|c|}{$\begin{array}{c}\text { Training } \\
\text { stage (age) }\end{array}$} & \multicolumn{3}{|c|}{$\begin{array}{c}\text { Stage of sports } \\
\text { improvement } \\
\text { (14-16 y.o.) }\end{array}$} & \multicolumn{3}{|c|}{$\begin{array}{l}\text { Stage of the highest } \\
\text { sports skill } \\
\text { (17 y.o. and older) }\end{array}$} & \multirow{2}{*}{ 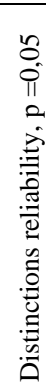 } \\
\hline № & 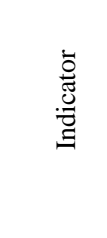 & 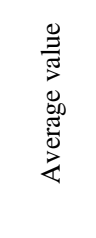 & 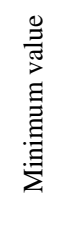 & 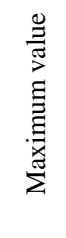 & 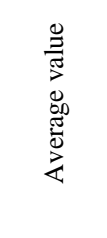 & 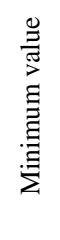 & 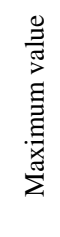 & \\
\hline 1 & $\begin{array}{l}\text { Body } \\
\text { length, } \\
\text { cm }\end{array}$ & $\begin{array}{l}173,56 \\
\pm 5,07\end{array}$ & $\begin{array}{c}162, \\
50\end{array}$ & $\begin{array}{c}181, \\
00\end{array}$ & $\begin{array}{l}175,40 \\
\pm 5,86\end{array}$ & $\begin{array}{c}166, \\
00\end{array}$ & $\begin{array}{c}189, \\
00\end{array}$ & no \\
\hline 2 & $\begin{array}{l}\text { Weight, } \\
\mathrm{kg}\end{array}$ & $\begin{array}{c}61 \pm 4,8 \\
4 \\
\end{array}$ & 53 & 70 & $\begin{array}{c}67 \pm 6,1 \\
0 \\
\end{array}$ & 58 & 77 & $\begin{array}{l}\text { exi } \\
\text { sts }\end{array}$ \\
\hline 3 & $\begin{array}{l}\text { Weight- } \\
\text { growth } \\
\text { index }\end{array}$ & $\begin{array}{c}352 \pm 26 \\
, 07\end{array}$ & 308 & 400 & $\begin{array}{c}380 \pm 27 \\
, 27\end{array}$ & 334 & 428 & $\begin{array}{l}\text { exi } \\
\text { sts }\end{array}$ \\
\hline 4 & $\begin{array}{l}\text { Body } \\
\text { mass } \\
\text { index }\end{array}$ & $\begin{array}{c}20 \pm 1,6 \\
2\end{array}$ & 17 & 23 & $\begin{array}{c}22 \pm 1,3 \\
6\end{array}$ & 19 & 24 & $\begin{array}{l}\text { exi } \\
\text { sts }\end{array}$ \\
\hline
\end{tabular}

Significant differences can be observed in weight indicators of sportswomen, weight-growth index and body mass index. Female athletes all listed indicators values at the stage of the highest sports skill (HSS) are higher. Both the maximum and minimum values of each indicator are high.

As for growth of athletes, reliable differences of its indicators were not found. This does say that girls on average reach their maximum body length by the age of 1416 years. At the same time, the minimum and maximum body length values for senior female tennis players are greater, indicating a possible change in body length of junior female tennis players.

Comparison of female tennis players physical fitness indicators training at different stages of long-term training gives reason to suggest that in no indicator assessing different forms and manifestations of different physical qualities was established reliably significant differences. However, by carefully analysing the results presented in table 2, it can be noted that 3 speed abilities indicators from 4 , all speed and power indicators, 2 coordination abilities indicators from 3 and 1 flexibility indicator from 2 of female tennis players at the HSS stage tend to improve. All indicators assessing types of endurance, one of which is necessary in case of short point draw (up to $10 \mathrm{~s}$ ), and the second one in case of longer ralley [8,9], are better of female tennis players at the stage of sports improvement, i.e. in 14-16 year-olds. The determined is in some contradiction with existing provisions in theory of sports training $[10,11$, $12]$.
TABLE II. PHYSICAL FITNESS INDICATORS OF HIGH QUALIFICATION FEMALE TENNIS PLAYERS TRAINING AT STAGES OF SPORTS SPECIALIZATION AND HIGHER SPORTS SKILL

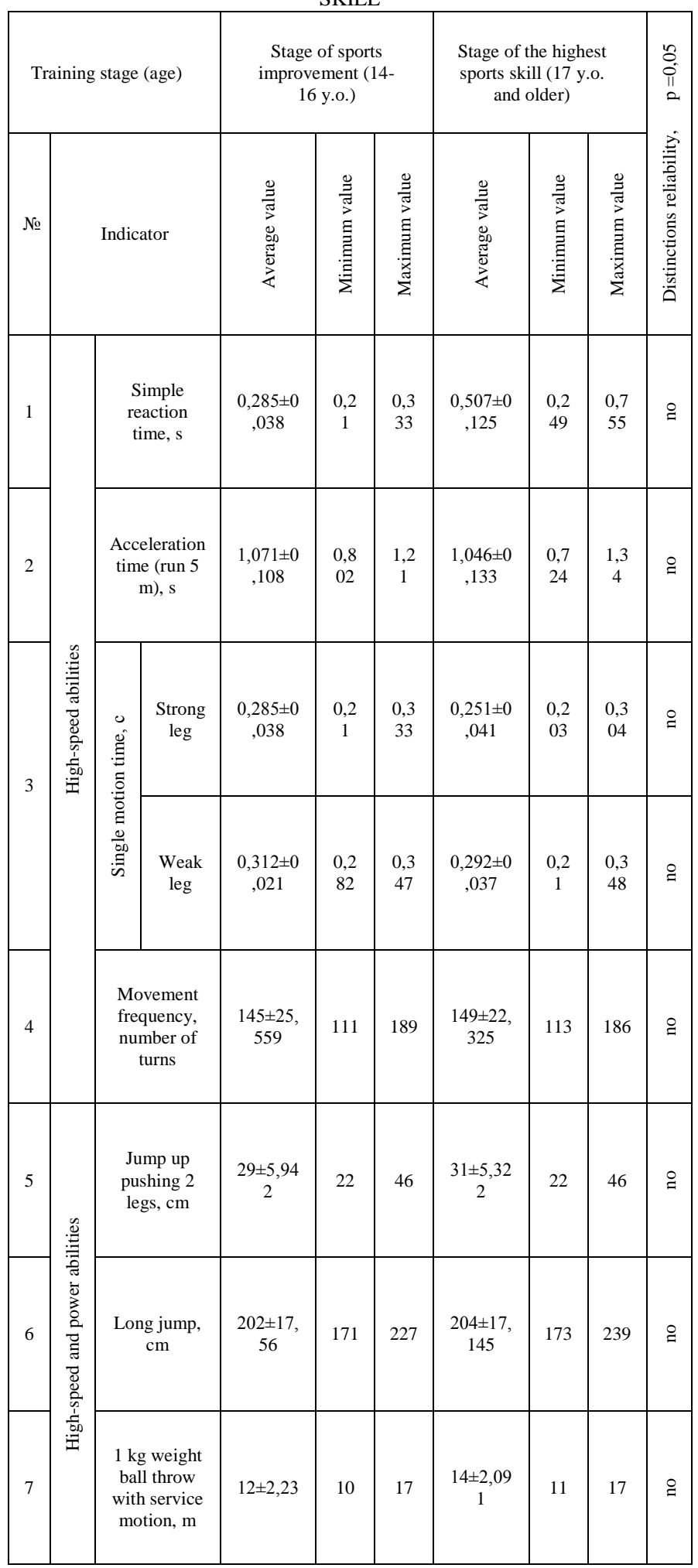


TABLE III. FUNCTIONAL FITNESS INDICATORS OF HIGH

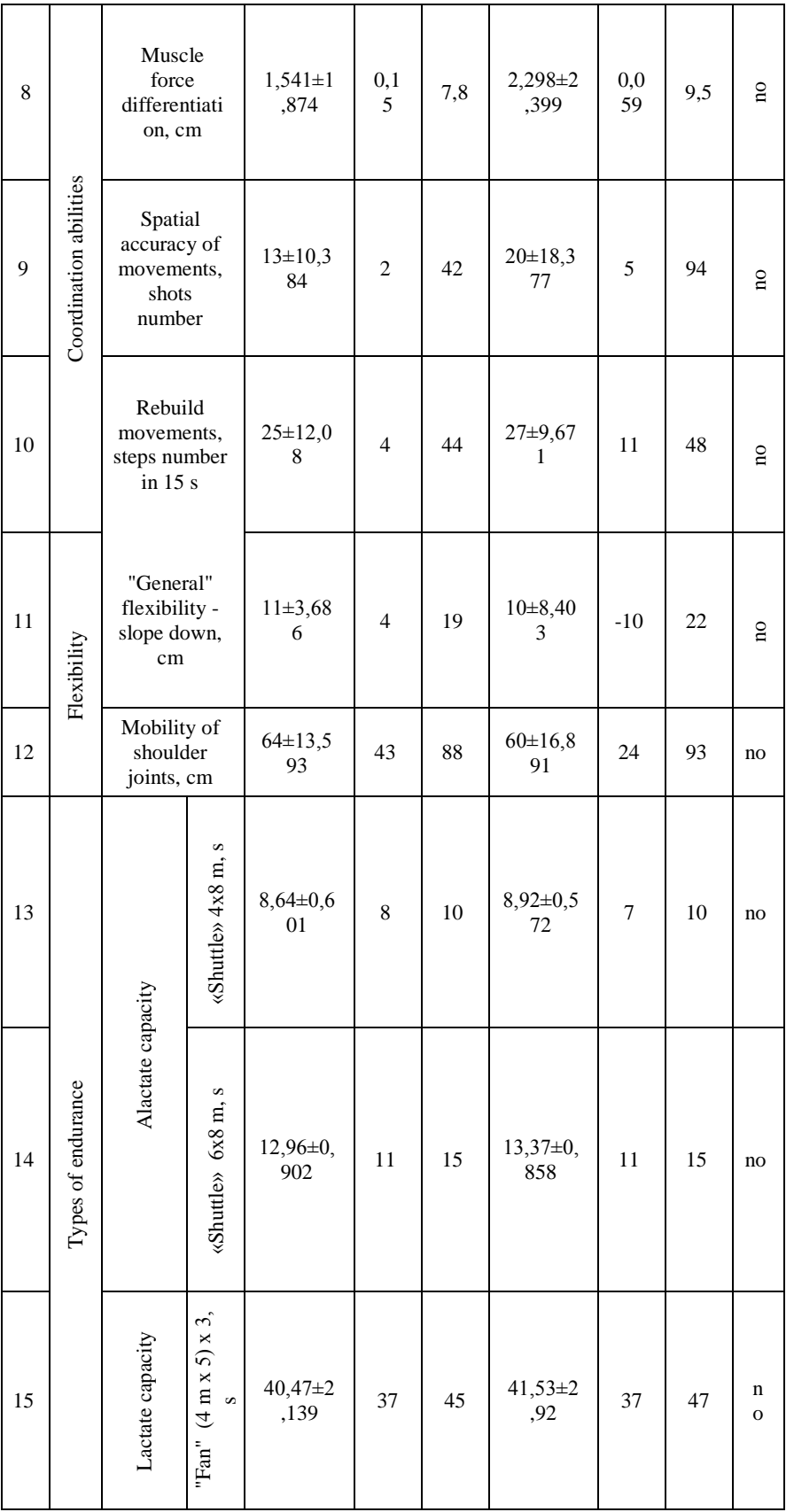

The differences identified, despite the fact that they are not reliable in terms of mathematical statistics, can be significant when drawing a point, game, and the match as a whole.

Results of functional fitness of high qualification female tennis players are presented in table III.
QUALIFICATION FEMALE TENNIS PLAYERS TRAINING AT

STAGES OF SPORTS SPECIALIZATION AND HIGHER SPORTS SKILL

\begin{tabular}{|c|c|c|c|c|c|c|c|c|}
\hline \multicolumn{2}{|c|}{$\begin{array}{l}\text { Training } \\
\text { stage } \\
\text { (age) }\end{array}$} & \multicolumn{3}{|c|}{$\begin{array}{c}\text { Stage of sports } \\
\text { improvement (14-16 } \\
\text { y.o.) } \\
\end{array}$} & \multicolumn{3}{|c|}{$\begin{array}{l}\text { Stage of the highest sports } \\
\text { skill (17 y.o. and older) }\end{array}$} & \multirow{2}{*}{ 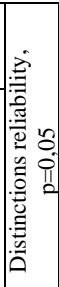 } \\
\hline № & $\begin{array}{c}\text { Indic } \\
\text { ator }\end{array}$ & 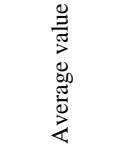 & 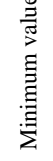 & 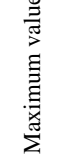 & 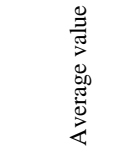 & 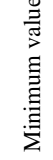 & 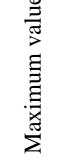 & \\
\hline 1 & $\begin{array}{l}\mathrm{VO} 2 \\
\mathrm{AeT} \\
1 / \mathrm{min}\end{array}$ & $\begin{array}{c}1,56 \pm 0,17 \\
4\end{array}$ & 1,34 & 1,87 & $1,5 \pm 0,281$ & 1,06 & 2,04 & @ \\
\hline 2 & $\begin{array}{l}\mathrm{VO} 2 \\
\mathrm{AeT}, \\
\mathrm{ml} / \mathrm{kg} \\
/ \mathrm{min}\end{array}$ & $\begin{array}{c}25,3 \pm 3,80 \\
2\end{array}$ & 19 & 32 & $22,64 \pm 3,749$ & 15 & 28 & \& \\
\hline 3 & $\begin{array}{l}\mathrm{HR} \\
\mathrm{AeT} \text {, } \\
\mathrm{b} / \mathrm{min}\end{array}$ & $131 \pm 9,216$ & 111 & 145 & $128 \pm 17,636$ & 94 & 165 & 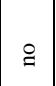 \\
\hline 4 & $\begin{array}{l}\mathrm{VO} 2 \\
\mathrm{AT} \\
1 / \mathrm{min}\end{array}$ & $\begin{array}{c}2,42 \pm 0,22 \\
5\end{array}$ & 1,89 & 2,83 & $2,62 \pm 0,386$ & 1,95 & 3,31 & 巳 \\
\hline 5 & $\begin{array}{l}\mathrm{VO} 2 \\
\mathrm{AT}, \\
\mathrm{ml} / \mathrm{kg} \\
/ \mathrm{min}\end{array}$ & $\begin{array}{c}39,82 \pm 4,7 \\
33\end{array}$ & 33 & 48 & $39,14 \pm 4,00$ & 30 & 46 & 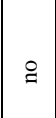 \\
\hline 6 & $\begin{array}{l}\mathrm{VO} 2 \\
\text { AT } \\
\text { from } \\
\mathrm{VO} 2 \\
\mathrm{Max}, \\
\%\end{array}$ & $\begin{array}{c}80,02 \pm 6,4 \\
9\end{array}$ & 65 & 89,7 & $81,7 \pm 4,716$ & 73 & 91 & 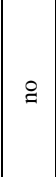 \\
\hline 7 & $\begin{array}{l}\mathrm{HR} \\
\mathrm{AT}, \\
\mathrm{b} / \mathrm{min}\end{array}$ & $164 \pm 8,47$ & 145 & 175 & $166 \pm 9,963$ & 144 & 182 & $\stackrel{\circ}{g}$ \\
\hline 8 & $\begin{array}{l}\text { Vent. } \\
\text { equiv } \\
.(\%)\end{array}$ & $\begin{array}{c}30,41 \pm 4,2 \\
45\end{array}$ & 22,6 & 35,5 & $32,21 \pm 2,912$ & 26,7 & 37,1 & 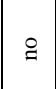 \\
\hline 9 & $\begin{array}{l}\mathrm{VO} 2 \\
\mathrm{Max} \\
1 / \min \end{array}$ & $\begin{array}{c}3,04 \pm 0,18 \\
1\end{array}$ & 2,71 & 3,44 & $3,21 \pm 0,442$ & 2,46 & 4,18 & ̊ \\
\hline
\end{tabular}


stages of long-term training, indicates the need to make

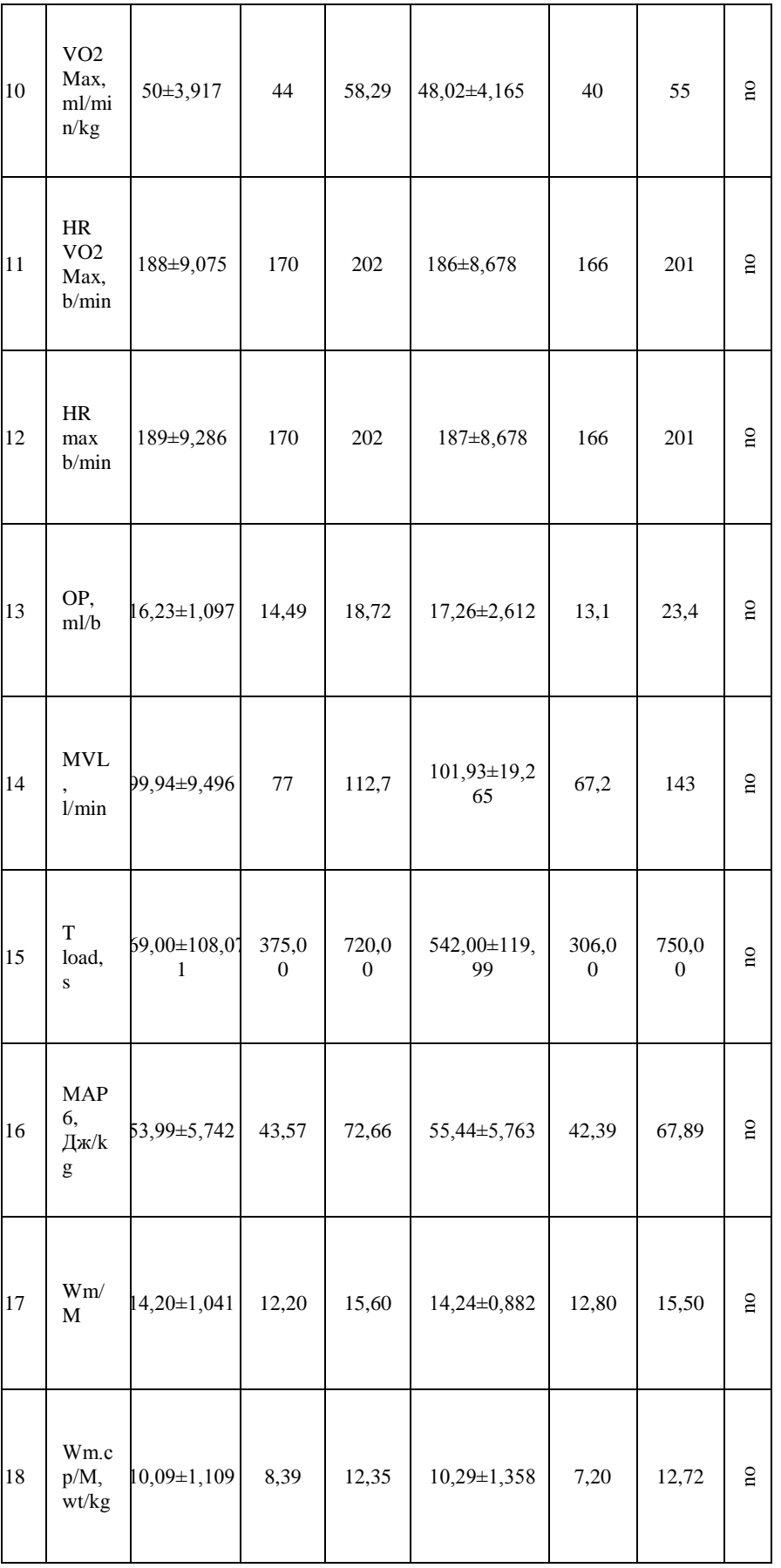

There were also no significant differences between the functional fitness indicators. In 8 indicators out of 18 there are slightly better results of female tennis players at the stage of HSS. In 10 indicators they lose to younger ones. They have worse such important indicators for playing the game as VO2at $\mathrm{ml} / \mathrm{kg} / \mathrm{min}$, ventilation equivalent $\mathrm{VE}$, VO2max $\mathrm{ml} / \mathrm{kg} / \mathrm{mn}$, t work s.

\section{IV.CONCLUSION}

Absence of statistically significant differences in indicators of physical and functional fitness of high qualification female tennis players training at different adjustments to the training system. First of all, it concerns female athletes at the stage of HSS. Most of them take part in excessive number of tournaments with the aim of obtaining points and promotion in the rating. For this reason the period of competitions is extended and very little time remains on developing physical training, improvement of technical-tactical actions (TTA). Studies carried out earlier [5] show that competitive practice does not support physical qualities at the level achieved in the preparatory period with the optimal combination of general training (GT) and special training (ST) means. Currently, participating in a large number of tournaments, tennis players score points. If the points sum divide by the number of tournaments, it turns out that the "cost" of tournament in points is very low. To increase it - it is necessary to raise tournament "cost". In this regard it is necessary to clarify the optimal number of tournaments in which the female athlete will actually be able to participate, having earned the necessary number of points.

During the released time to carry out training work specifying tasks of work, combination of general training means (GT) and special training (ST) and means itself, as well as methods of training.

\section{References}

[1] Matveev, L.P. Sports theory basics and athletes training system. Kiev.: Olympic literature. 1999, 318.

[2] Abramova T.F., Nikitina T.M., Yakutovich N.M., Tarasova L. V., Iordanskaya F. A. High-skill oarsmen physical preparation markers differentiated importance in conditions of centralized training taking into account age category, Theory and physical culture practice. Moscow, Russia. 2018, 11, pp. 6-8.

[3] Zebzeev, V.V. Analysis of morphofunctional features of crosscountry skiers - biathlonists of competitive readiness different types, Science and sport: modern tendency. 2019, 1 (22), pp. 97-101.

[4] Skorodumova, A.P. Modern tennis: training basics. M.: «FiS». 1984, 160 .

[5] Skorodumova, A.P. Tennis. How to achieve success. M.: «PROPRESS». 1994, 176.

[6] Skorodumova, A.P., Trukhachev A.A., Kuznetsova O.V., Baranov I.S. Tests for assessment of physical and functional fitness of tennis players and model characteristics of their readiness, M.: Federal State Budgetary Institution Federal Center of Preparation of a Sports Reserve. 2013, 40

[7] Skorodumova, A.P. 6-14 years old male tennis players physical fitness control: study guide. M. 2018, 64 .

[8] Cheremisinov, V.N. Power ensuring of intense muscular activity, TVT Division, Moscow, Russia. 2016, 136.

[9] Jansen, P. HR, lactate and trainings on endurance, Tuloma. 2016, 157.

[10] Bompa, T. and Buczcichelli, K. A. Sports training periodization. M.: «Sport». 2016, 383.

[11] Volokov N. I., Nesen E.N., Osipenko A.A., Korsun S.N. Biochemistry of muscle activity. Kiev.: Olympic literature. 2000, 503.

[12] Platonov, V.N. Sports training periodization. General theory and its practical application. Kiev.: Olimp. Lit. 2014, 624.

[13] Kuznetsova Z.M., Kuznetsov S.A., Ovchinnikov Yu.D., Golovko P.V. Analysis of the morphological-functional indices connection degree in throwing among athletes. The Russian Journal of Physical Education and Sport. 2018, 13(2), pp. 44-51. DOI: 10.14526/02_2018_308. 
[14] Aleksandr S. Kuznetsov. Russian Professor's meeting. Russian Journal of Physical Education and Sport. Pp. 2019, 14(1), 17-22. 